\title{
Effect of nitrogen on surface morphology of layers
}

\author{
Z. Pokorný, V. Hrubý*, Z. Studený \\ Department of Mechanical Engineering, University of Defence in Brno, Kounicova 65, 66210 Brno, Czech Republic
}

Received 3 June 2015, received in revised form 2 November 2015, accepted 3 November 2015

\begin{abstract}
This article deals with the chemical composition and mechanical properties of plasma nitrided layers after chemical-heat treatment process. Experiments are focused on the creation of clusters of nitrogen on the surface of evaluated material. The peculiarity of this experiment is established sophisticated technological process suitable for creation of nitride layers inside cavities with really small diameters. The conditions of the process are designed to provide strictly defined nitride layers with defined parameters. In this case, the nitrided layers were applied to bars of steel $32 \mathrm{CrMoV} 12-10$ that were subsequently evaluated by metallographic, GDOES, XRD microanalysis and microhardness methods. The results of measurement showed trends of the chemical composition of alloying elements after chemical-heat treated process through the length of the cavity. Plasma nitriding process was applied for increasing the surface hardness of material in deep cavities. In the evaluation of surface structure the new typical marks on the surface of material after plasma nitriding process were found. Mechanical properties of evaluated material were significantly improved.
\end{abstract}

K e y w o r d s: nitriding, chemical composition, microhardness, nitrided layer, clusters

\section{Introduction}

The term plasma nitriding minds also in general definition a surface treatment of the material, when the use of the process of anomalous glow discharge causes gradual saturation of the surface of components by nitrogen comprised in the plasma under predetermined temperatures and pressures [1]. Nitrides occur inside the material as a result of the nitriding process. The technology of plasma nitriding can figure among the latest types of nitriding. The aim of the process is to achieve an enhanced surface hardness, better wear resistance, reduced friction coefficient, increase fatigue limit or corrosion resistance. The developed nitrides of iron in the diffusion layer caused a low increase of microhardness. The main elements that caused improving properties are alloying elements as molybdenum, vanadium, aluminium or chrome. During plasma nitriding process, two layers are mostly created. On the top of material the compound layer consisting of $\varepsilon-\mathrm{Fe}_{2-3} \mathrm{~N}$ and $\gamma-\mathrm{Fe}_{4} \mathrm{~N}$ phase should be established [2]. This type of layer is very hard and brittle with good friction and anticorrosion properties
[2]. This layer is usually evaluated by metallographic methods. The thickness and hardness of $\gamma^{\prime}-\mathrm{Fe}_{4} \mathrm{~N}$ depends on quantity and quality of alloying elements [3]. The composition of diffusion nitrided layers can be effectively influenced by the chemical composition of nitriding atmosphere [4].

This article describes the chemical and mechanical properties of nitrided layers that were created in inner part of cavities. The depth of diffusion layer (Nht thickness) of mentioned sample is compared with the content of alloying elements and nitrogen along the whole length of the cavity. This study deals with chemical and mechanical properties of nitriding layers that were created by the pressure of $600 \mathrm{~Pa}$. The microstructure of cross-sectional structure was evaluated by confocal laser microscopy Olympus LEXT OLS 3000 and subsequently by scanning electron microscope SEM Philips 505 in a display of secondary electrons. SEM microscope was used for evaluation of clusters of nitrogen on the surface of inner part of the cavity as well. The chemical composition of steel was verified for selected chemical elements by GDOES/Bulk method on LECO SA 2000 spectrom-

*Corresponding author: e-mail address: vojtech.hruby@unob.cz 
Table 1. Temperatures of heat-treated steels

\begin{tabular}{lc}
\hline Procedure & Temperature $\left({ }^{\circ} \mathrm{C}\right)$ \\
\hline Oil quenching & 940 \\
Salt tempering & 650 \\
\hline
\end{tabular}

Table 2. Parameters of plasma nitriding process

\begin{tabular}{lc}
\hline Temperature $\left({ }^{\circ} \mathrm{C}\right)$ & 500 \\
Duration $(\mathrm{h})$ & 6 \\
Gas flow $\mathrm{H}_{2} / \mathrm{N}_{2}\left(\mathrm{l} \mathrm{min}^{-1}\right)$ & $24 / 8$ \\
Bias $(\mathrm{V})$ & 530 \\
Pressure $(\mathrm{Pa})$ & 600 \\
Pulse length $(\mu \mathrm{s})$ & 100 \\
\hline
\end{tabular}

eter, and local measurement of composition was carried out on SEM Philips 505 microscope with micro analyzer Philips Edax 9900. The thickness and microhardness of plasma nitrided layers were measured by microhardness method in accordance with DIN 50190 standard on automatic microhardness tester LECO LM 247 AT [4]. The thickness of the compound layer was measured by optical microscope OLYMPUS GX 51 equipped by software ANALYSIS.

\section{Experimental work}

Samples of $32 \mathrm{CrMoV} 12-10$ steel in the untreated state were cylinder bored with a diameter of $8 \mathrm{~mm}$. Samples of length $500 \mathrm{~mm}$ were heat treated in accordance with Table 1.

The confirmation of the structure composition was analysed by confocal laser microscope Olympus LEXT OLS 3000. The initial structure feature of steel was assessed as homogeneous which corresponded to a low-carbon tempered martensite (Fig. 1).

A microhardness of heat-treated steel of samples was $550 \mathrm{HV0.05}$. Plasma nitriding was carried out in PN 60/60 RÜBIG furnace according to Table 2. The charge consisted of 3 cylindrical samples (cavities with diameter $8 \mathrm{~mm}$ ) which were plasma nitrided at the pressure of $600 \mathrm{~Pa}$ for $6 \mathrm{~h}$.

Plasma nitriding process was provided by automatized system RUBIG that allows one or two-stage process. The selection of suitable process depends on required layer properties (mechanical and corrosion). After plasma nitriding process, the samples with the inner diameter of $8 \mathrm{~mm}$ were cut off. The length of the first sample was chosen greater for the safe nitriding of cavity surface over a length of $30 \mathrm{~mm}$; the annular samples had a length of $12 \mathrm{~mm}$. The lengths of next

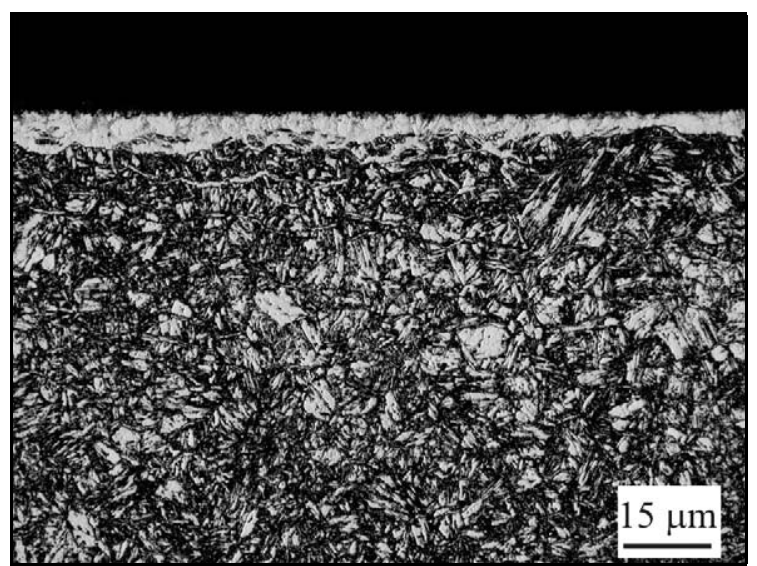

Fig. 1. The chemically etched optical cross-sectional structure of heat-treated $32 \mathrm{CrMoV} 12-10$ steel; nitrided compound layer on the top and diffusion layer below.

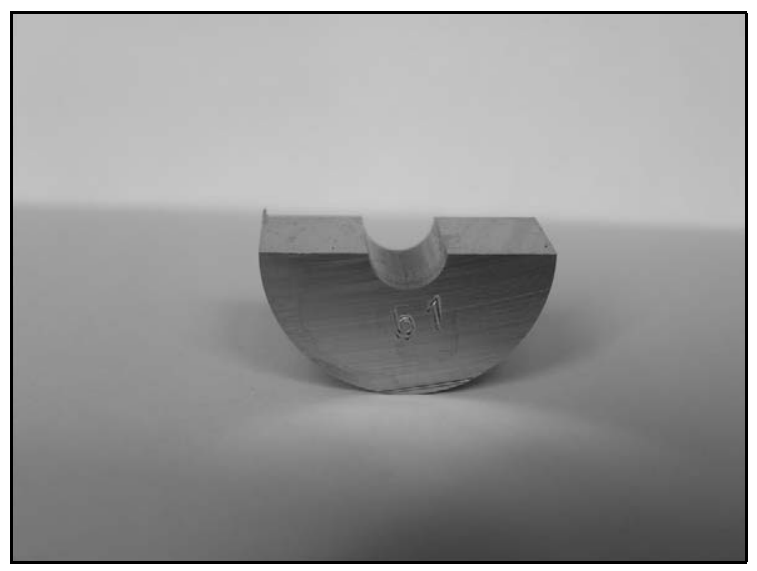

Fig. 2. The sample after the axial cut.

samples were following: $30,42,54,66,78,90,102$, $114,126,138,150,162,174,186,198,210,222,234$, 246, $258 \mathrm{~mm}$. All samples were labelled and again axially split into halves so that the cutting plane passed through the axis of the cavity as accurately as possible (Fig. 2).

All samples were wet grounded using silicon carbide paper with grit from 80 down to 2000 and subsequently polished. After nital etching, the confocal laser microscope LEXT OLS 3000 with an outstanding resolution of $0.12 \mu \mathrm{m}$ and magnification range from $120 \times$ to $12400 \times$ was used for observation and crossstructure documentation (Fig. 1).

The thickness of created compound layer was evaluated by optical microscope Olympus GX 51 in combination with Analysis software programme (Fig. 3, Table 4).

As a part of the experiments, the chemical composition of material was measured by GDOES/Bulk method on reference samples (Table 3 ). 
Table 3. Chemical composition of 32CrMoV12-10 steel (wt.\%)

\begin{tabular}{cccccccc}
\hline $\mathrm{C}$ & $\mathrm{Mn}$ & $\mathrm{Si}$ & $\mathrm{Cr}$ & $\mathrm{Mo}$ & $\mathrm{V}$ & $\mathrm{P}$ & $\mathrm{S}$ \\
\hline \multicolumn{7}{c}{ GDOES/Bulk } & \\
\hline 0.30 & 0.47 & 0.25 & 2.95 & 0.89 & 0.28 & 0.002 & 0.001 \\
\hline $0.30-0.35$ & $<0.60$ & $<0.35$ & $2.80-3.20$ & $0.80-1.20$ & $0.25-0.35$ & $<0.025$ & $<0.010$ \\
\hline
\end{tabular}

Table 4 . Trends of microhardness thickness and chemical composition after plasma nitriding process $500^{\circ} \mathrm{C} / 6 \mathrm{~h} / 600 \mathrm{~Pa}$

\begin{tabular}{|c|c|c|c|c|c|c|c|c|c|c|}
\hline \multirow{2}{*}{$\begin{array}{l}\text { Length } \\
(\mathrm{mm})\end{array}$} & \multirow{2}{*}{$\begin{array}{c}\text { Sample } \\
\text { No. }\end{array}$} & \multirow{2}{*}{$\begin{array}{l}\text { Nht } \\
\text { thickness } \\
(\mathrm{mm})\end{array}$} & \multirow{2}{*}{$\begin{array}{c}\text { Compound layer } \\
\text { thickness } \\
(\mu \mathrm{m})\end{array}$} & \multicolumn{7}{|c|}{ Chemical composition (wt.\%) } \\
\hline & & & & $\mathrm{N}$ & $\mathrm{V}$ & $\mathrm{Si}$ & Mo & $\mathrm{Cr}$ & $\mathrm{Mn}$ & $\mathrm{Fe}$ \\
\hline 30 & 6.0 & 0.27 & 9.50 & 6.51 & 0.43 & 0.72 & 1.34 & 3.44 & 0.98 & 86.58 \\
\hline 42 & 6.1 & 0.25 & 9.50 & 5.87 & 0.39 & 0.81 & 1.19 & 3.29 & 1.27 & 87.18 \\
\hline 54 & 6.2 & 0.24 & 7.15 & 6.41 & 0.41 & 0.86 & 1.25 & 3.36 & 1.03 & 86.68 \\
\hline 66 & 6.3 & 0.21 & 6.19 & 6.51 & 0.35 & 0.84 & 1.15 & 3.33 & 1.13 & 86.69 \\
\hline 78 & 6.4 & 0.20 & 6.01 & 6.52 & 0.34 & 0.80 & 1.01 & 3.25 & 1.09 & 87.00 \\
\hline 90 & 6.5 & 0.17 & 5.78 & 6.45 & 0.38 & 1.05 & 1.45 & 3.42 & 1.21 & 86.04 \\
\hline 102 & 6.6 & 0.16 & 5.67 & 6.54 & 0.40 & 0.82 & 1.21 & 3.39 & 1.13 & 86.51 \\
\hline 114 & 6.7 & 0.16 & 6.24 & 6.65 & 0.43 & 0.83 & 1.22 & 3.31 & 1.20 & 86.39 \\
\hline 126 & 6.8 & 0.15 & 5.07 & 6.61 & 0.41 & 0.94 & 1.30 & 3.31 & 1.23 & 86.20 \\
\hline 138 & 6.9 & 0.14 & 3.69 & 6.28 & 0.43 & 0.90 & 1.18 & 3.39 & 1.34 & 86.53 \\
\hline 150 & 6.10 & 0.14 & 3.40 & 6.43 & 0.42 & 0.95 & 1.19 & 3.44 & 1.06 & 86.50 \\
\hline 162 & 6.11 & 0.12 & 3.88 & 6.44 & 0.43 & 0.81 & 1.29 & 3.55 & 1.1 & 87.38 \\
\hline 174 & 6.12 & 0.12 & 3.78 & 6.54 & 0.38 & 0.81 & 1.22 & 3.32 & 1.07 & 86.65 \\
\hline 186 & 6.13 & 0.12 & 3.78 & 6.20 & 0.45 & 0.89 & 1.43 & 3.41 & 1.24 & 86.38 \\
\hline 198 & 6.14 & 0.11 & 3.31 & 5.41 & 0.30 & 0.88 & 1.32 & 3.33 & 1.06 & 87.69 \\
\hline 210 & 6.15 & 0.10 & 3.34 & 4.35 & 0.41 & 0.86 & 1.42 & 3.38 & 1.13 & 88.44 \\
\hline 222 & 6.16 & 0.10 & 2.67 & 3.71 & 0.39 & 0.87 & 1.28 & 3.40 & 1.06 & 89.29 \\
\hline 234 & 6.17 & 0.09 & 2.35 & 2.52 & 0.39 & 0.85 & 1.32 & 3.48 & 1.12 & 90.31 \\
\hline 246 & 6.18 & 0.08 & 2.56 & 2.61 & 0.35 & 0.87 & 1.30 & 3.30 & 1.03 & 90.80 \\
\hline 258 & 6.19 & 0.04 & 2.75 & 3.09 & 0.34 & 0.72 & 1.23 & 3.27 & 0.93 & 90.43 \\
\hline 270 & 6.20 & 0.05 & 1.08 & 4.69 & 0.35 & 0.79 & 1.09 & 3.31 & 0.98 & 88.78 \\
\hline
\end{tabular}

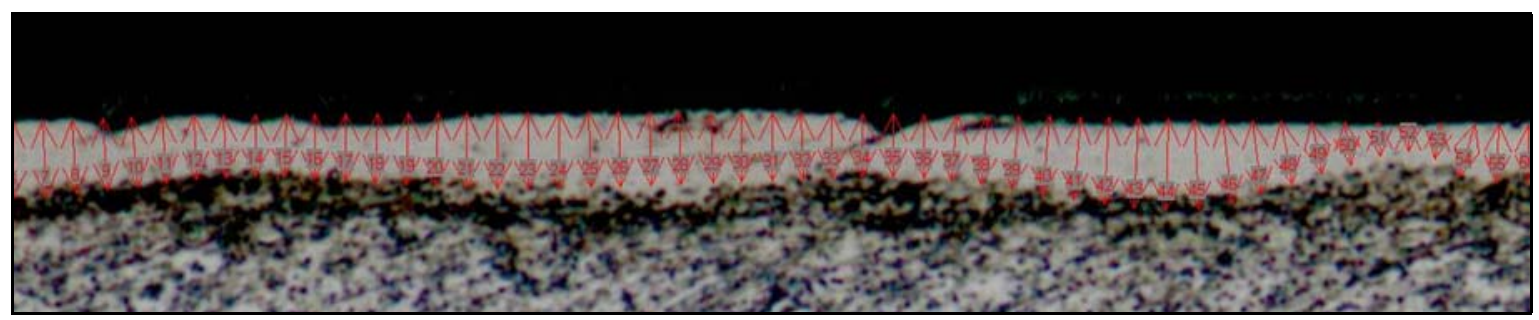

Fig. 3. Evaluation of compound layer thickness.

Glow discharge optical spectroscopy (GDOES) measurements were performed in LECO SA-2000, with argon glow discharge plasma excitation source, calibration of nitrogen: JK41-1N and NSC4A standards.

Besides, the microhardness and thickness of nitride diffusion layer were measured on each of mentioned samples, using Vickers microhardness method on the automatic tester LECO LM 247 AT equipped with software AMH43. The microhardness was measured at $50 \mathrm{~g}$ load and $10 \mathrm{~s}$ dwell time. The depth of nitride layer was practically determined by 30 indentations from the nitrided surface to the core of sample. The spacing of individual indentation was set to $0.01 \mathrm{~mm}$. All measurements were done under the same conditions, incl. sample preparation. The results are displayed in Table 4, Fig. 4.

After plasma nitriding process, the microhardness 


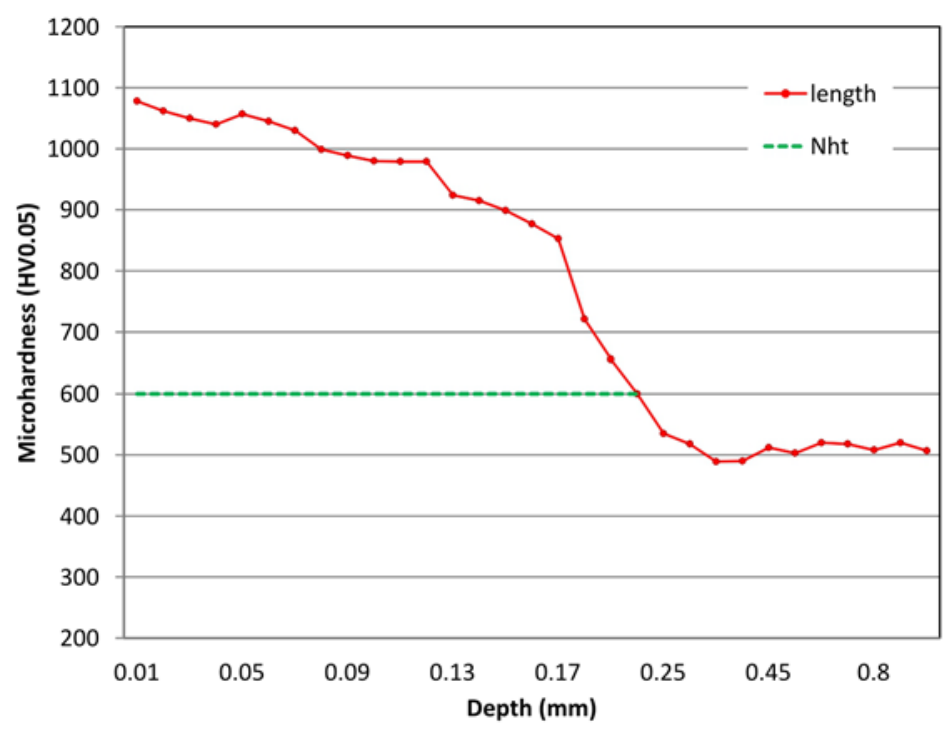

Fig. 4. Microhardness depth profile, measured in length $78 \mathrm{~mm}$; plasma nitriding process $500{ }^{\circ} \mathrm{C} / 6 \mathrm{~h} / 600 \mathrm{~Pa}$.

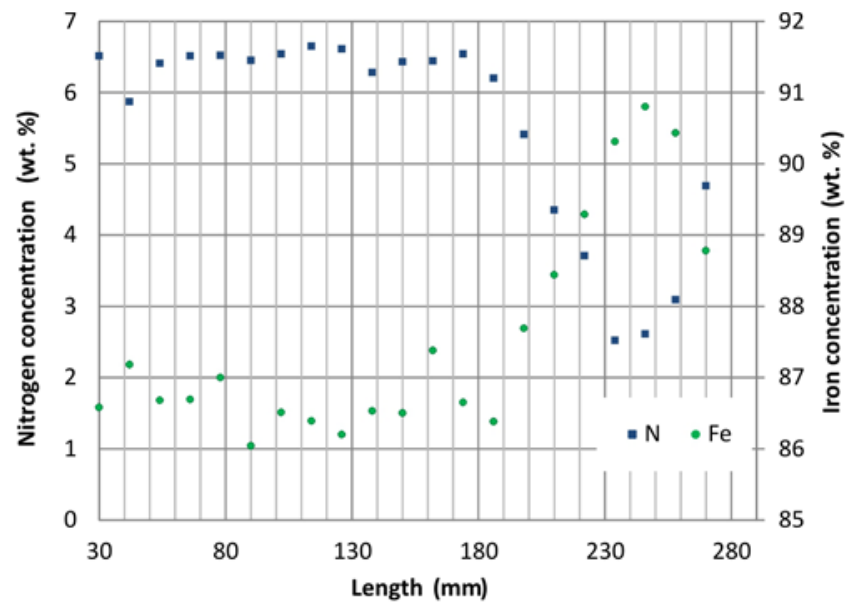

Fig. 5. Chemical analysis of alloying elements Fe, N.

of the tempered martensitic structure increased from 550 to 1150 HV0.05. The measurement from length $78 \mathrm{~mm}$ of inside part of the cavity is shown in Fig. 4 .

The local chemical compositions of plasma nitrided layers in length of the cavity were observed by SEM method in combination with energy dispersive micro analyser PHILIPS EDAX 9900. The results of measurements nitrogen $(\mathrm{N} \mathrm{K})$, silicon ( $\mathrm{Si} \mathrm{K})$, molybdenum (Mo L), chrome (Cr K), manganese (Mn K) and iron (Fe K) were performed from two local spaces by $25 \times$ magnification by the method of surface analysis. Graphic illustration of measured values of concentration of elements in plasma nitrided surface of inner part of the cavity is displayed in Table 4, Fig. 5. The changes in the chemical composition of cavity surface were measured at an accelerating voltage of $20 \mathrm{kV}$ and exposure time $50 \mathrm{~s}$.

Cluster sizes were measured for orientation in several areas on each of samples in the display of sec- ondary electrons. Measurements were done over the length of $270 \mathrm{~mm}$.

\section{Results}

Heat-treated samples with a diameter of $8 \mathrm{~mm}$ which were plasma nitrided at a pressure of $600 \mathrm{~Pa}$ were investigated. Microhardness of depth profiles of plasma nitrided layers confirmed enhancement of microhardness about $500 \mathrm{HV} 0.05$, which is shown in Fig. 4. Nht thickness of plasma nitrided layer was measured in accordance with DIN 50190 standard [4].

The inner part of cavity reached a very high level of Nht thickness of nitride diffusion layer. The values of thickness were measured by using the method of microhardness testing. Also, compound zone in the same area was evaluated as very favourable. All results of measurements of the thickness of nitrided 
Ta ble 5. Cluster dimension average values on surface of the cavity

\begin{tabular}{lrrrrrrrrrr}
\hline Length & 6.0 & 6.1 & 6.2 & 6.3 & 6.4 & 6.5 & 6.6 & 6.7 & 6.8 & 6.9 \\
\hline Average $d(\mathrm{~nm})$ & 146 & 185 & 283 & 190 & 246 & 311 & 280 & 221 & 246 & 213 \\
Deviation $s_{\mathrm{d}}(\mathrm{nm})$ & 41 & 128 & 163 & 82 & 127 & 143 & 163 & 68 & 137 & 101 \\
\hline Sample & 6.10 & 6.11 & 6.12 & 6.13 & 6.14 & 6.15 & 6.16 & 6.17 & 6.18 & 6.19 \\
\hline Average $d(\mathrm{~nm})$ & 208 & 177 & 250 & 233 & 281 & 246 & 248 & 206 & 222 & 158 \\
Deviation $s_{\mathrm{d}}(\mathrm{nm})$ & 88 & 81 & 151 & 149 & 178 & 124 & 224 & 126 & 152 & 129 \\
\hline
\end{tabular}

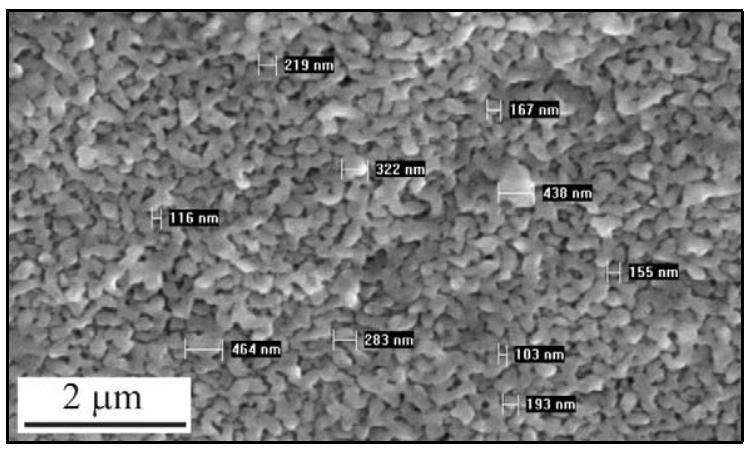

Fig. 6. Surface morphology of sample in length $90 \mathrm{~mm}$ evaluated by the electron microscope, magnified $10000 \times$

layers are displayed in Table 4. Mentioned measurements displayed in Table 4 show the decreasing of the thickness of diffusion and compound layer. In length $30 \mathrm{~mm}$ the value of the thickness of diffusion layer $0.27 \mathrm{~mm}$ was determined, the thickness of compound zone was evaluated to $9.5 \mu \mathrm{m}$. Another measurement in length $42 \mathrm{~mm}$ shows the decreasing of the thickness of diffusion layer about $0.02 \mathrm{~mm}$, in the case of the compound zone the decreasing is noticeable in length $54 \mathrm{~mm}$ about approx. $2 \mu \mathrm{m}$. The trend of microhardness measured on the cross-sectional structure is given in Fig. 4. The same areas of inner part of the cavity were investigated by using SEM (Fig. 6). The reason for measurement was to find the chemical composition of the inner part after plasma nitriding process and, of course, to find a quantity of nitrogen in mentioned areas (see Table 4, Fig. 5). The relationship of the nitrogen content in the surface layer with the thickness of the nitrided layer is apparent from Fig. 7. During experiments, the surface morphology of each sample in inner part was investigated as well. The clusters created on the surface of the cavity were documented by using SEM and are displayed in Table 5 and Fig. 6 . The documentation of clusters is given in Fig. 6 .

\section{Conclusions}

The results of experimental work show the capa-

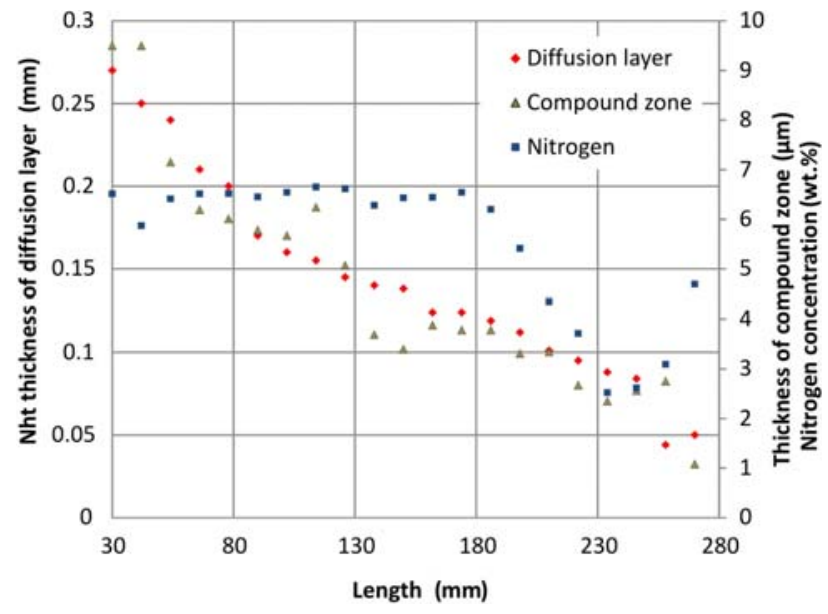

Fig. 7. Chemical analysis of nitrogen compared with trends of nitrided layers.

bilities of plasma nitriding process. In many cases, the application of diffusion layer or coatings to the inner part of bars is very difficult. By using this technology, it is possible to apply required layers to defined areas of selected machine parts. Determined results show that plasma nitriding process is applicable not only to flat surfaces. These created nitrided layers improve corrosion resistance and mechanical properties of steel. Created nitrided layers can be used in automotive and weapon industry. It was proven that the diameter of the cavity has an influence on the plasma nitriding in length in accordance with Fig. 7. Peaks, which were established during plasma nitriding process (Fig. 7), have connection with plasma density and concentration of nitrogen (Table 4). Figure 7 shows that concentration of nitrogen has a significant influence on the thickness of nitrided layers. The content of nitrogen in surface depends on the effectivity of plasma nitrided process, especially on parameters: voltage, pressure, and temperature. The content of the chemical composition of alloying elements is not changed by plasma nitriding process what is displayed in Table 4, except nitrogen. The clusters created on the surface show the effectivity of glow discharge during the process. The quantity of nitrogen on the sur- 
face has no relationship to the thickness of diffusion layer. The measurements show that the decreasing of nitrogen content has no relationship to the size of clusters.

\section{Acknowledgements}

The work was supported by a Research Project for the Development of the Organization of the Dept. of Mechanical Engineering, UoD "Promoting Research, Science and Innovation in the Field of Engineering".

\section{References}

[1] Jonsta, P., Marsalek, P., Havlik, J., Jonsta, Z., Valicek, J.: Key Eng. Mat., 607, 2014, p. 11. doi:10.4028/www.scientific.net/KEM.607.11

[2] Croccolo, D., Cristofolini, L., Bandini, M., Freddi, A.: Fatigue Fract. Eng. M, 25, 2002, p. 695. doi:10.1046/j.1460-2695.2002.00533.x

[3] Horak, V., Kulish, V., Hruby, V., Mrazkova, T.: AIP Conf. Proc., 1493, 2012, p. 486. doi:10.1063/1.4765532

[4] Hassani-Gangaraj, S. M., Moridi, A., Guagliano, M., Ghidini, A., Boniardi, M.: Int. J. Fatigue, 62, 2014, p. 67. doi:10.1016/j.ijfatigue.2013.04.017

[5] ČSN ISO 14577-1 METALLIC MATERIALS - Instrumented Indentation Test for Hardness and Materials Parameters - Part 1: Test Method. 